\title{
Effects of Losartan and Ramipril on the connexin expression in a rabbit balloon injury model
}

\author{
Xujuan Li, Deqiang Li, Jinfeng Duan, Junzhu Chen, Wei Cai and Voonthow Kok
}

The First Affiliated Hospital, College of Medicine, Zhejiang University, No.79, Qingchun Road, Hangzhou, Zhejiang Province, P. R. China, 310003.

Accepted 27 July, 2011

\begin{abstract}
Intercellular gap junction (GJ) plays a pivotal role in the proliferation and transformation of vascular smooth muscle cells (VSMCs). This study was designed to test the hypothesis that expressions of the component proteins of gap junctions, connexins 40 and 43 (Cx40 and Cx43), are up-regulated in arteries subjected to balloon injury and that this up-regulation can be suppressed by statin therapy. Transmission electron microscopy (TEM) revealed that there were abundant GJ between neointimal SMCs but fewer and smaller GJ after losartan and ramipril treatment. Reverse transcription-polymerase chain reaction and Western blot analysis showed the messenger ribonucleic acid (mRNA) and protein expressions of $\mathrm{Cx} 40$ and $\mathrm{Cx} 43$ were elevated after injury, and these elevations were suppressed by losartan and ramipril. Immunostaining showed the Cx40 and Cx43 expressions were consistently enhanced in the neointimal area after injury, which was decreased by losartan and ramipril treatment. Balloon injury causes up-regulation of $\mathrm{Cx40}$ and $\mathrm{Cx43}$ in neointimal SMCs. angiotensin-converting enzyme inhibitors (ACEIs) and $\mathrm{AT}_{1}$ antagonist losartan can reduce the proliferation of SMCs, suggesting the rennin-angiotensin system (RAS) system plays an important role in the remodeling of GJ in the VSMCs under pathological conditions.
\end{abstract}

Key words: Vascular smooth muscle cell, gap junction, connexin, balloon angioplasty, statin.

\section{INTRODUCTION}

Intercellular gap junction (GJ) has been shown to play a pivotal role in the transformation of vascular smooth muscle cells (VSMCs) from the differentiated contractile state to the activated synthetic state (Matsushita et al., 2007; Rama et al., 2006). GJ channels are composed of connexins, a multigene family of conserved proteins. As a main component of GJ channels, the connexins determine

\footnotetext{
*Corresponding author. E-mail: doc1998@yeah.net Fax: 86-
} 0571-56723002. Tel: 86-0571-56723002.

Abbreviations: GJ, Gap junction; VSMCs, vascular smooth muscle cells; Cx40, connexins40; Cx43, connexins43; ACEIs, angiotensin-converting enzyme inhibitors; RAS, renin angiotensin system; RT-PCR, reverse transcriptasepolymerase chain reaction; PBS, phosphate buffered saline; ECL, enhanced chemiluminescent; RT, reverse transcription; mRNA, messenger ribonucleic acid; SD, standard deviation; PTCA, percutaneous transluminal coronary angioplasty. the permeability and conductance of the channels (Kanaporis et al., 2011). The main component of connexins expressed in the conduit VSMCs is connexin43 (Cx43). The significance of GJ in the vascular response to injury and diseases has been demonstrated in vitro and in vivo. It has been shown that following the transformation of VSMCs from differentiated contractile state to the activated synthetic state, the expression of Cx43 in the VSMCs increases three-fold and the diameter of GJ is enlarged (Yeh et al., 1997). Relatively high expression of Cx43 is also observed in the migrating and proliferating VSMCs in the neointima of rat carotid artery subjected to balloon catheter induced injury (Yeh et al., 1997). Besides, Cx43 expression during the proliferation of VSMCs is up-regulated in the arterial walls of rabbits following hypercholesterolemia or balloon injury (Wang et al., 2005). During the migration and proliferation of VSMCs, Cx43 plays an important role in the intercellular signal transduction.

Angiotensin II, a powerful vasoconstrictor, c an activate the 
mitosis of VSMCs leading to multiplication of VSMCs, proliferation of fibroblasts, deposition of collagens, and resulting in arterial sclerosis (Rudijanto, 2007). It has been shown that angiotensin-converting enzyme inhibitors (ACEIs) and Angiotensin II (Ang II) type $1\left(\mathrm{AT}_{1}\right)$ receptor antagonists can prevent SMCs from Ang II induced proliferation and migration (Dendorfer et al., 2005). Other study also show that Ang II can up-regulate the Cx43 expression in the hepatic epithelial cells of WB rats, and therefore result in changes in the cellular metabolic conditions and secondary messengers (Cai et al., 2006). Researches on drug development reveal that $\mathrm{AT}_{1}$ antagonist losartan can inhibit the highly elevated expression of $\mathrm{Cx} 43$ in the ventricular myocytes of neonatal rats (Zhao et al., 2008). Study also demonstrated that $\mathrm{AT}_{1}$ antagonist can inhibit the upregulation of $\mathrm{Cx} 43$ in rat ventricular myocytes subjected to periodic mechanical stretching (Shyu et al., 2001), suggesting that renin angiotensin system (RAS) played an important role in the remodeling of $\mathrm{GJ}$ in ventricular myocytes under pathological conditions (Sun, 2010). Although Cx43 has been studied extensively, its expression and function are largely unknown.

The present study was to investigate the roles of $\mathrm{Cx} 40$ and $\mathrm{Cx} 43$ in the migration and proliferation of VSMCs, and to determine the effect of $A T_{1}$ antagonists and ACEls on the expressions of $\mathrm{C} \times 40$ and $\mathrm{C} \times 43$ aiming to explore the mechanism underlying the protective effect of $A T_{1}$ antagonists and ACEls.

\section{MATERIALS AND METHODS}

\section{Animals}

A total of 35 male New Zealand white rabbits weighing $2.5 \sim 3.0 \mathrm{~kg}$ were provided by Animal Center of Medical College, Zhejiang University, and intravenously anesthetized with 20\% Ethylurethanm $(5 \mathrm{ml} / \mathrm{kg}$ ). The femoral arteries were exposed by an incision below the inguinal ligament. Heparin sulfate (1000 U) was intravenously administered to prevent thrombosis. After local administration of 2 $\mathrm{mL}$ of $1 \%$ lidocaine, a $2.5 \mathrm{~F}$ angioplasty catheter was introduced under the fluoroscopic guidance in an over-the-wire system into the right iliac artery. This catheter possesses the triple functions of balloon inflation. The $3.0 \mathrm{~mm}$-diameter, $20 \mathrm{~mm}$-long balloon was inflated with contrast medium at the right iliac artery immediately distal to the aortic bifurcation (a reliable and reproducible landmark for the removal of the vessels at a later date). The balloon was then retracted $20 \mathrm{~mm}$ from the bifurcation and then deflated. This procedure was repeated three times to ensure complete endothelial denudation. The femoral artery was then ligated. After operation, benzylpenicillin sodium $(400000 \mathrm{U} / \mathrm{d})$ was intramuscularly administered for three consecutive days. Rabbits were divided into five groups: balloon injury+losartan (Merck and Co., Inc., Whitehouse Station, $\mathrm{NJ})(n=7,10 \mathrm{mg} / \mathrm{kg} / \mathrm{d}$ orally); balloon injury+ramipril (Novartis Pharmaceuticals, Basel, Switzerland) ( $n=7$, $0.5 \mathrm{mg} / \mathrm{kg} / \mathrm{d}$ orally); balloon injury without drug treatment $(n=7)$; sham operation ( $n=7$, operation without endothelial denudation); and normal control group $(n=7)$. Losartan and ramipril were administered to the rabbits after operation. All animals were killed at 2 weeks after these procedures with an overdose of intravenous pentobarbital sodium (150 mg). The injured were collected and separated into four for immunohistochemistry, transmission electron microscopy, Western blot analysis and reverse transcriptasepolymerase chain reaction (RT-PCR) as described below. This study was carried out in accordance with the rules of Zhejiang University Ethics Committee.

\section{Plasma Cholesterol Level}

Peripheral blood was collected from the ear vein immediately before operation and just before the sacrifice. Plasma cholesterol was measured with an automated analyzer (Type 7170, Hitachi Corp., Tokyo, Japan).

\section{Pathologic Examination and Immunochemistry}

Iliac arteries were carefully collected and post-fixed in 4\% paraformaldehyde in phosphate-buffered saline (PBS) $(\mathrm{pH} 7.4)$ overnight at $4^{\circ} \mathrm{C}$. Tissues were rinsed with PBS for $1 \mathrm{~h}$ and dehydrated in grade ethanol. Then, tissues were transparentization with chloroform and xylene and embedded in paraffin. Tissues were sectioned into 6-Om sections followed by deparaffinization. Endogenous peroxidase activity was quenched by incubation with $0.3 \%$ hydrogen peroxide in methanol for $10 \mathrm{~min}$ at room temperature. The sections were either stained with hematoxylin and eosin or incubated with anti-Cx43 monoclonal antibody (Zymed Laboratories Inc, Carlsbad, CA) or anti-Cx40 monoclonal antibody (Alpha Diagnostic International Inc, San Antonio, TX) (1:1000) in blocking buffer [containing $2 \%$ bovine serum albumin (BSA) in phosphate buffered saline (PBS)] at room temperature overnight. After washing with PBS, the sections were incubated with the secondary antibody conjugated to peroxidase (Histofine simplestain kit, Nichivei, Japan) for $30 \mathrm{~min}$ at room temperature. The sections were visualized with 3, 3'-diaminobenzidine and hydrogen peroxide, and counterstained with hematoxylin.

\section{Transmission electron microscopy}

Samples were fixed in $2.5 \%$ glutaraldehyde in $0.1 \mathrm{~mol} / \mathrm{L}$ sodium cacodylate buffer ( $\mathrm{pH} 7.3$ ) for $2 \mathrm{~h}$. The specimens were then rinsed in buffer, post-fixed in cacodylate-buffered $2 \% \mathrm{OsO}_{4}$, stained en bloc in uranyl acetate, dehydrated in ethanol, and embedded in epoxy resin according to standard protocol. Ultrathin sections were stained with uranyl acetate and lead citrate and examined under a Philips TECNA10 electron microscope (FEI Co., Hillsboro, OR). For quantitative measurement of the GJ the relative ratios to the control group in size and volume were calculated in sham group, balloon injured, and balloon injured plus drug treatment groups.

\section{Western blot assay}

Protein extracts were prepared in a lysis buffer and then repeatedly aspirated (20 times) through a 23-gauge needle. Crude extracts were centrifuged at $4^{\circ} \mathrm{C}$ for $30 \mathrm{~min}$ at $10,000 \mathrm{~g}$ and the supernatants were subjected to protein quantification. Total proteins (20 Og for $\mathrm{Cx} 40$ and $4 \mathrm{Og}$ for $\mathrm{Cx} 43$ ) were mixed with loading buffer and aliquots were loaded onto a $12.5 \%$ polyacrylamide sodium dodecyl sulfate gel. After separation, proteins were transferred onto nitrocellulose membranes. Membranes were blocked for 30 min in PBS containing $5 \%$ non-fat milk and $0.1 \%$ Tween and subsequently incubated overnight with either the anti-Cx43 monoclonal antibody (Zymed Laboratories Inc.) or anti-Cx40 monoclonal antibody (Alpha Diagnostic International Inc.) $(1: 1,000)$ or anti-actin antibody (PharMingen, San Jose, CA) (1:500). After washing in $0.1 \%$ Tween in PBS, membranes were treated for $1 \mathrm{~h}$ with the horseradish peroxidase-conjugated secondary antibodies (Chemicon, 
Table 1. Body weight and plasma cholesterol levels before and after operation and treatment.

\begin{tabular}{lccccc}
\hline \multirow{2}{*}{ Group } & \multirow{2}{n}{} & \multicolumn{2}{c}{ Plasma cholesterol (mmol/L) } & \multicolumn{2}{c}{ Body weight $\mathbf{( k g )}$} \\
\cline { 3 - 6 } & & Baseline & Before sacrifice & Baseline & Before sacrifice \\
\hline Normal control & 7 & $1.35 \pm 0.08$ & $1.37 \pm 0.12$ & $2.87 \pm 0.21$ & $2.97 \pm 0.24$ \\
Sham operation & 7 & $1.35 \pm 0.11$ & $1.36 \pm 0.10$ & $2.81 \pm 0.20$ & $2.93 \pm 0.21$ \\
Operation & 7 & $1.36 \pm 0.13$ & $1.35 \pm 0.12$ & $2.88 \pm 0.23$ & $2.97 \pm 0.25$ \\
Operation + losartan & 7 & $1.35 \pm 0.12^{\# \#++}$ & $1.34 \pm 0.16$ & $2.86 \pm 0.25$ & $2.96 \pm 0.22$ \\
Operation + ramipril & 7 & $1.36 \pm 0.15^{\#+++}$ & $1.35 \pm 0.14$ & $2.84 \pm 0.23$ & $2.98 \pm 0.27$ \\
\hline
\end{tabular}

Results are expressed as mean \pm SD. ${ }^{\# \#} P<0.01$ vs. operation group; ${ }^{++} P<0.01$ vs. baseline.

Temecula, CA) (anti-rabbit: 1:1,000; anti-mouse: 1:500). The time of incubation in enhanced chemiluminescent $(E C L)$ detection reagents and that of exposure to Hyperfilm (Amersham-Pharmacia, Buckinghamshire, UK) were identical in all experimental conditions. The bands were scanned and the optical intensity of these bands was quantitatively densitometric analysis using Kodak Digital Science 1D 2.0 Image software.

\section{Reverse transcription polymerase chain reaction}

Total ribonucleic acid (RNA) was isolated from tissues using Trizol reagent (Life Technologies, Gaithersburg, MD). Total RNA (2.5 g) were reverse transcribed into complimentary deoxyribonucleic acid (cDNA) in the $50 \mathrm{~L}$ reaction mixtures containing $200 \mathrm{U}$ of recombinant M-MLV reverse transcriptase (Superscript II, GIBCO$\mathrm{BRL}$ ) and oligo $\mathrm{dT}_{15}$ as primer. The reverse transcription (RT) was carried out at $42^{\circ} \mathrm{C}$ for $60 \mathrm{~min}$ followed by an denaturation at $94^{\circ} \mathrm{C}$ for $10 \mathrm{~min}$. The products of RT were stored at $-70^{\circ} \mathrm{C}$. The amount of RNA was determined by measuring the absorbance at $260 \mathrm{~nm}$. The oligonucleotide primers were as follows: a) GAPDH-1: 5'-GCG CCT GGT CAC CAG GGC TGC TT-3', and GAPDH-2, 5'-TGC CGA AGT GGT CGT GGA TGA CCT-3'; b) Cx40-1: 5'-ATG CAC ACT GTG CGC ATG CAG GA-3' and Cx40-2, 5'-CAG GTG GTA GAG TTC AGC CAG-3'; c) Cx43-1, 5'-CAT CTT CAT GCT GGT GGT GT-3', and Cx43-2, 5'-TAG TTC GCC CAG TTT TGC TC-3'. Computerassisted primer selection (Gene Runner, Hastings Software) was conducted to determine the primer for Cx43. The PCR fragments were 399 bp for Cx40, 283 bp for Cx43, and 465 bp for GAPDH, which were consistent with the anticipated size of each gene.

mRNA expressions of $\mathrm{C} \times 40$ and $\mathrm{C} \times 43$ were determined by semiquantitative PCR using GAPDH as an internal reference. The samples were subjected to $28(\mathrm{C} \times 40)$ or $30(\mathrm{C} \times 43)$ cycles of amplification as follows: denaturation at $94^{\circ} \mathrm{C}$ for $5 \mathrm{~min}$, annealing at $57^{\circ} \mathrm{C}(\mathrm{C} \times 40)$ or $51^{\circ} \mathrm{C}(\mathrm{C} \times 43)$ for $45 \mathrm{~s}$ and extension at $72^{\circ} \mathrm{C}$ for 1 min. A final extension was also performed at $72^{\circ} \mathrm{C}$ for $10 \mathrm{~min}$. The products $(10 \mathrm{~L})$ of PCR were visualized on $2 \%$ agarose gel. The bands were captured by using a solid-state black-and-white video camera (Cohu Electronic, Irvine, CA), and the optical density of these bands was determined by using a Kodak Digital Science 1D 2.0 imaging software.

\section{Statistical analysis}

Data are presented as mean \pm standard deviation (SD). Comparisons between multiple groups were analyzed with one-way analysis of variance. Means between two groups were analyzed with a two-tailed Student $t$ test after an $F$ test for homogeneity of variances. If data failed to meet the requirements for parametric $t$ test, a Mann-Whitney $U$ test was used. A value of $P<0.05$ was considered statistically significant.

\section{RESULTS}

\section{Body weight and plasma cholesterol levels}

The body weight and plasma cholesterol levels before and after operation and drug treatment are shown in Table 1. There were no differences in the body weight and plasma cholesterol level before surgery among five groups. Body weight of rabbits increased in all groups after 2 weeks of treatment, but no difference in the body weight among five groups was detected. At the end of the 2-week treatment, the plasma cholesterol level was not significantly different in all groups from that before surgery, and no difference in the plasma cholesterol level was noted among five groups after treatment.

\section{Pathologic changes in the arteries}

In normal arteries, the elastic lamina was clear and intact, and the endothelium and SMCs were regularly arranged. After balloon injury, the elastic lamina became incomplete and neointima developed in the arterial wall. Abundant SMCs appeared near the internal elastic lamina, arranged irregularly and tended to grow toward the intima. Losartan markedly reduced the neointima area (Figure 1).

\section{Expressions of $\mathrm{Cx} 40$ and $\mathrm{Cx} 43$ in the arteries}

The expressions of $\mathrm{C} \times 40$ and $\mathrm{Cx} 43$ were observed in the SMCs all over the media in non-injured arteries of control rabbits. After balloon injury, the $\mathrm{C} \times 40$ and $\mathrm{Cx} 43$ expressions were significantly increased in both the media and neointima and this increase was more prominent in the latter. Losartan and ramipril markedly reduced the Cx43 expression in the balloon injured arteries, especially in the neointima area. The Cx40 expression was not significantly changed after both treatments (Figure 2 ). 


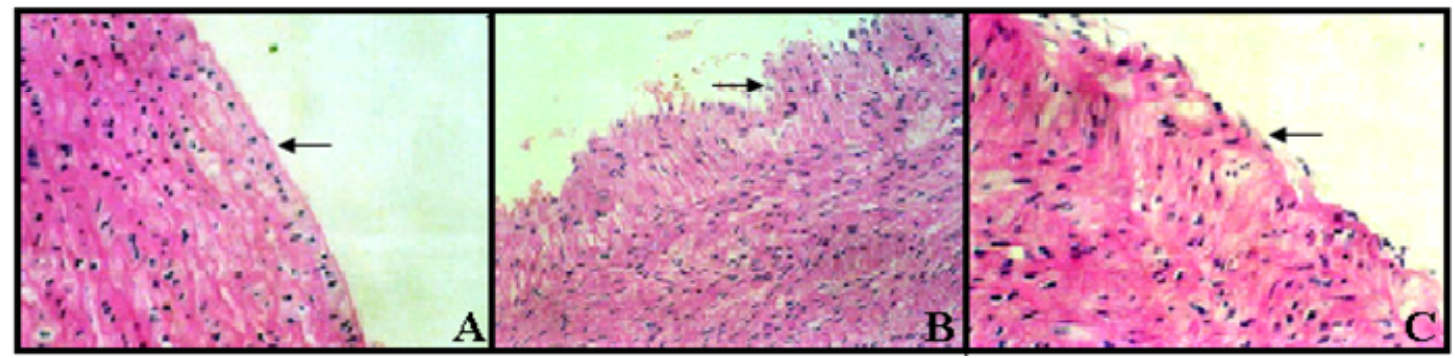

Figure 1. Hematoxylin/eosin staining of the iliac arterial wall of rabbits in the normal control group (A), the operation group (B), and the operation plus losartan group (C). A: the elastic lamina was clear and complete; endothelium and smooth muscle cells (arrow) were arranged regularly. B: the elastic lamina is incomplete and neointima appeared. Abundant smooth muscle cells near the internal elastic lamina were arranged irregularly and tended to grow toward the intima (arrow). C: after treatment with losartan, the neointima markedly decreased.

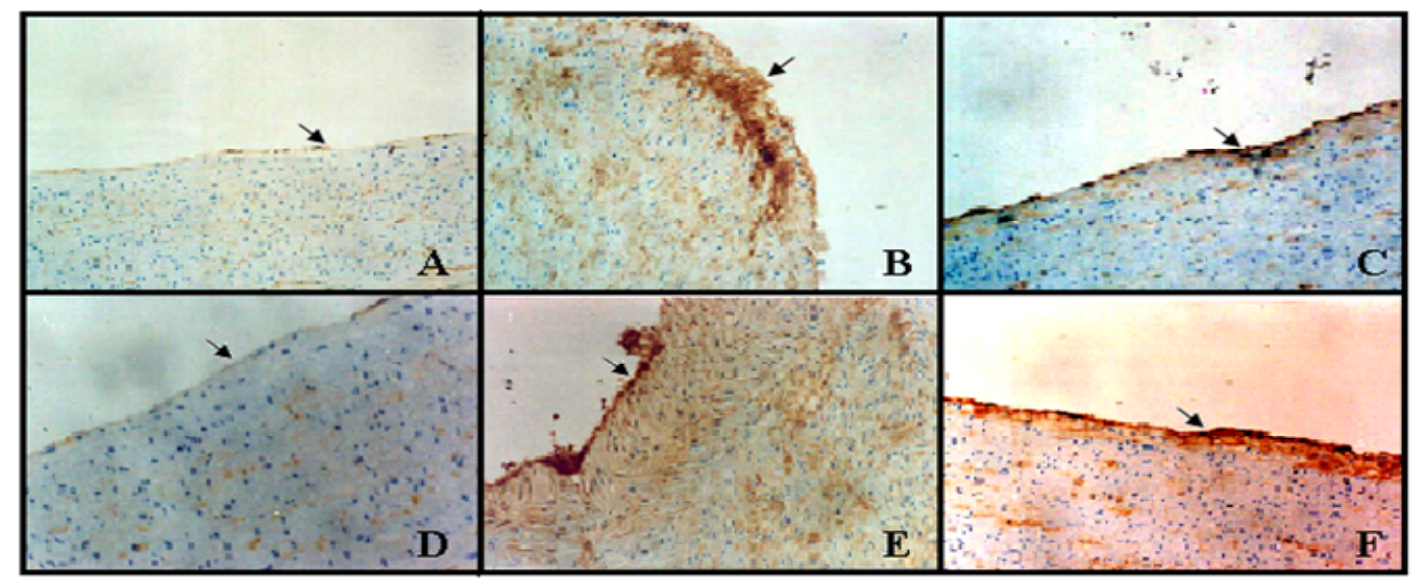

Figure 2. Immunohistochemistry for connexin40 $(C \times 40)$ and connexin43 $(C \times 43)$ in the rabbit iliac arteries in different groups. Cx40 expression is shown in panels A, B, and C and Cx43 expression D, E, and F. A: Cx40 expression (brown spots, arrow) in the media between SMCs in the rabbit iliac arteries from the control group. B: Cx40 expression in the arteries from the operation group. Cx40 expression was found in both the media and neointima but more prominent in the latter. C: Cx40 expression in the arteries from the operation plus losartan group. The Cx40 expression in the neointima of arteries was markedly reduced when compared with that in $\mathrm{C}$. The distribution of $\mathrm{Cx} 43$ was similar to that of $\mathrm{Cx} 40$.

\section{Changes in the GJ in the arteries}

When compared with normal controls, the GJ between SMCs of neointima in the balloon injured arteries was significantly increased. GJ was mainly observed between SMCs. After losartan and ramipril treatment, the volume and size of GJ between SMCs in the neointima were reduced. In addition, collagen fibers were also abundant in the neointimia (Figure 3).

\section{Protein and mRNA expressions of Cx40 and Cx43}

Both protein and mRNA expressions of $\mathrm{Cx} 40$ and $\mathrm{C} \times 43$ were significantly elevated in the rabbit iliac arteries with balloon injury. However, Losartan and ramipril treatment down-regulated the elevated protein and mRNA expressions of $\mathrm{C} \times 43$ in the balloon injured arteries, which was not observed in the protein and mRNA expressions of Cx40 (Figure 4).

\section{DISCUSSION}

GJ is one of the most ubiquitous and ancient forms of intercellular connections. In the adult mammals, most normal cells in solid tissues have functional gap junctional intercellular communication which is the only way for cells to directly exchange signals, allow the passive transportation of ions and low molecular weight molecules, and maintain the homeostasis and cellular growth in the multicellular organisms (Kjenseth et al., 2010; 

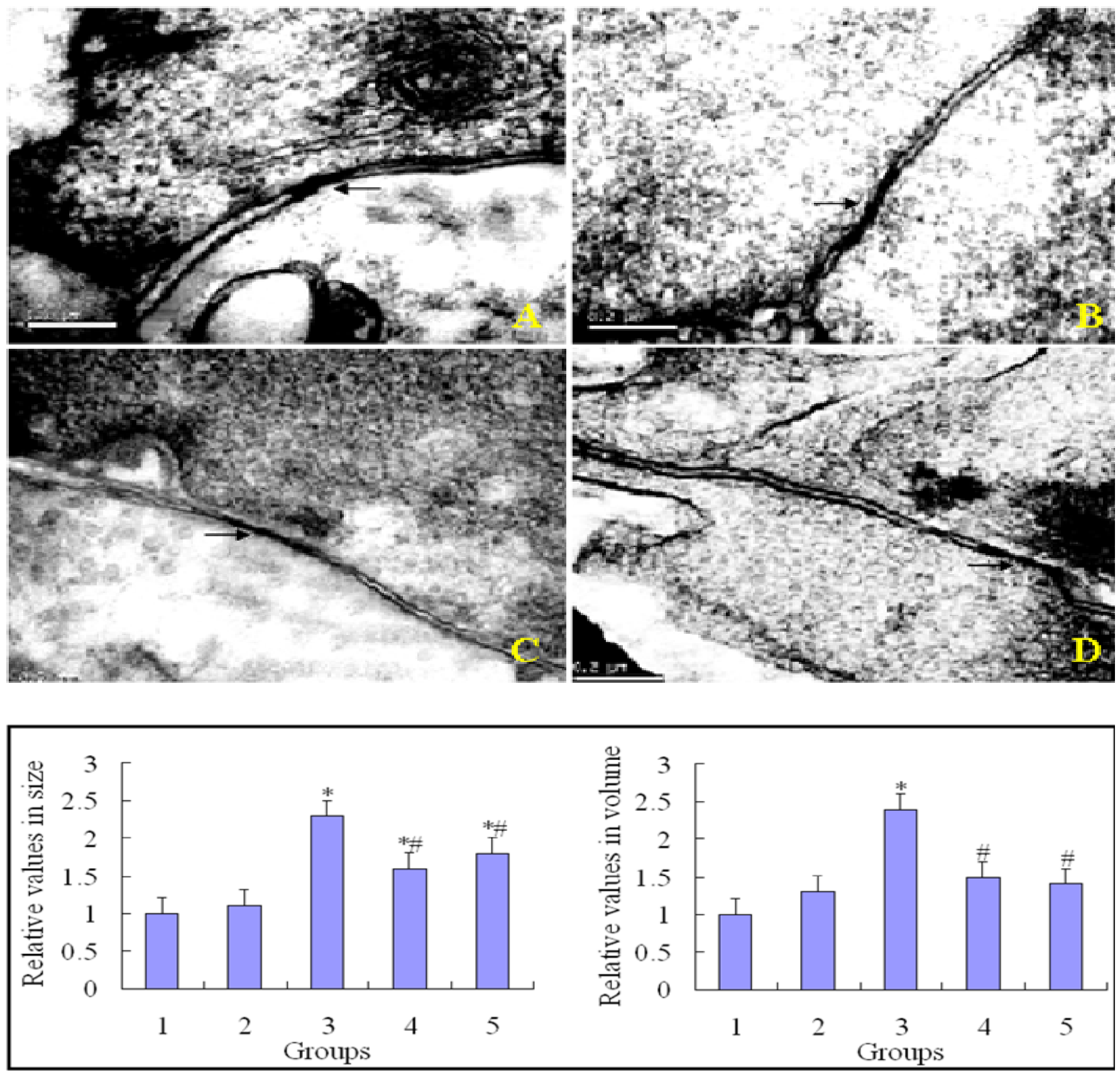

Figure 3. Ultrathin-section electronmicrographs of GJ between SMCs of rabbit iliac arteries from the normal control group (A), the operation group (B), the operation plus losartan group (C) and the operation plus ramipril group (D). Bar $=0.2 \mu \mathrm{m}$ for $A$, $B, C$ and $D)$. $65,000 \times$. Lower panel: Results of qualitative analysis in different groups. 1: normal control $(n=7)$; 2 : sham operation ( $n=7)$; 3: operation $(n=7)$; 4: operation + losartan $(n=7)$; 5 : operation + ramipril $(n=7)$. ${ }^{*} P<0.05$ vs. control group and sham operation group, ${ }^{\#} P<0.05$ vs. operation group.

Geng et al., 2007). The structural proteins comprising the GJ channels in mammalian cells are collectively called connexins. A family of over a dozen of highly evolutionarily-conserved and related genes (connexin genes) code for the connexins. All the known connexins are transmembrane proteins with four highly conservedhelical transmembrane domains and cytoplasmic amino and carboxyl termini (Harris, 2001). The GJ channelforming connexins belongs to a multigene family with at least fifteen members in mammalians so far. Connexins are expressed in a cell-, tissue-, and developmentspecific manner. However, different connexins have been identified in a same tissue or cell. For instance, Cx40, $\mathrm{C} \times 43$, and $\mathrm{C} \times 45$ are the three major connexins found in 

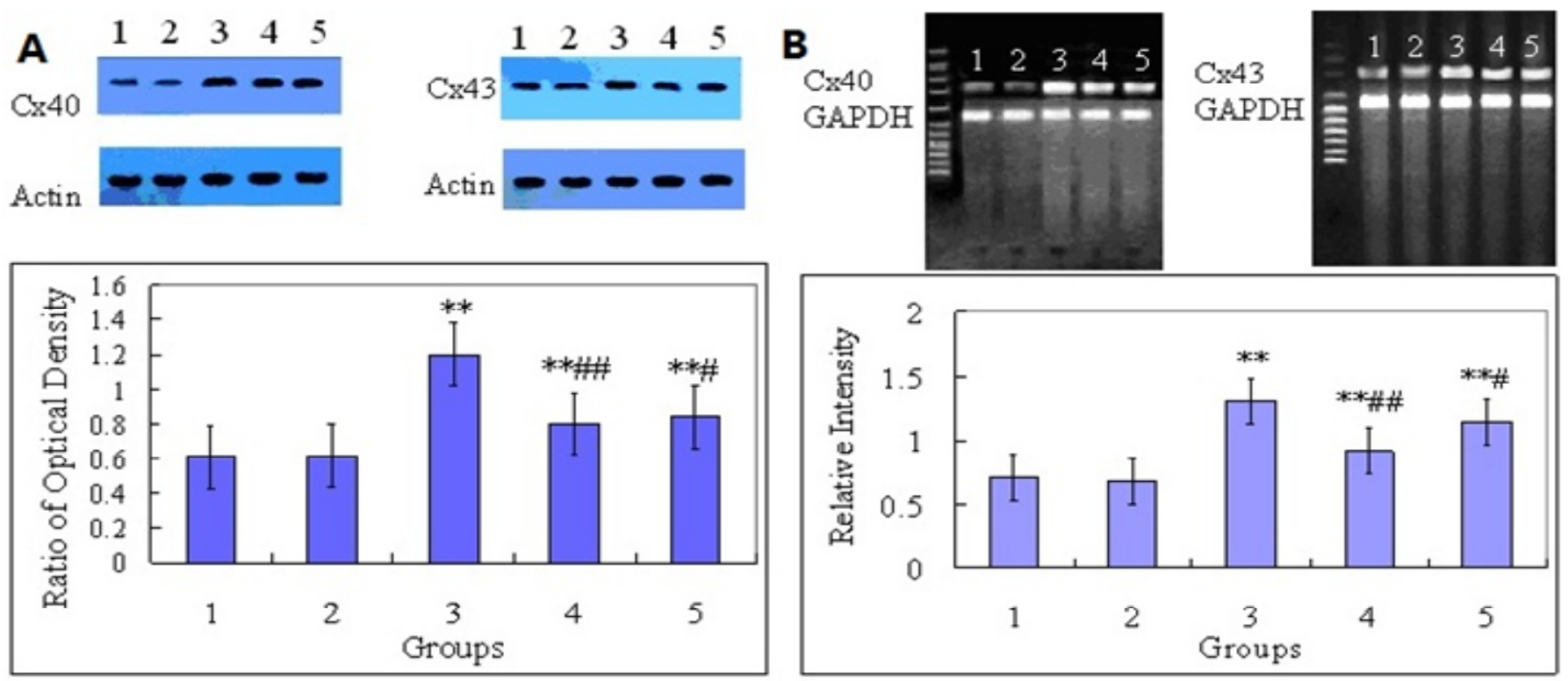

Figure 4. Protein expression (western blot analysis) of $\mathrm{C} x 40$ and $\mathrm{Cx} 43$ (left) and mRNA expression (RT-PCR) of Cx40 and Cx43 (right) in the rabbit iliac arteries in different groups. The lower panels are the results (mean \pm SD) from qualitative analysis. 1: normal control $(n=7)$; 2: sham operation $(n=7)$; 3: operation $(n=7)$; 4: operation + losartan $(n=7)$; 5: operation + ramipril $(n=7)$. * $P<0.01$ vs. control group and sham operation group, ${ }^{\# \#} P<0.01,{ }^{\#} P<0.05$ vs. operation group.

the myocardiac cells (Carlen et al., 2000), while Cx37, Cx40, and Cx43 are specific to VSMCs (Isakson et al., 2006).

In normal vascular wall, the integrity of endothelial cells is essential for the maintenance of the physiology of blood vessels. Study has demonstrated Cx40 and Cx43 are critical for the communication between endothelial cells and the integrity of endothelial cells. It is evident that the expressions of $\mathrm{C} \times 40$ and $\mathrm{C} \times 43$ are altered when the cultured SMCs transform from the contractile state to the synthetic state. Furthermore, experiment on the heterozygotic rat with congenital deficiency of $\mathrm{Cx} 43$ shows a decrease of atheromatous plaque by approximately $50 \%$ when compared with normal controls, indicating the $\mathrm{C} \times 43$ is essential for the atherosclerosis (Kwak et al., 2003). Accordingly, the role of GJ and connexins in the formation and growth of atheromatous plaque, and the restenosis following percutaneous transluminal coronary angioplasty (PTCA) has almost been clarified, and it is important to manipulate the function and regulation of GJ and connexins in order to reduce the occurrence of such lesions.

Lymphocytes express Cx43 following activation by lipopolysaccharide and appear to form GJ between endothelial cells after ischemia-reperfusion (Jara et al., 1995). Substances noxious to endothelial cells such as low-density lipoprotein, insulin, and hyperglycemia can interfere with the formation of GJ between endothelial cells. In the absence of intact GJ, the vasodilative effect of nitric oxide will be absent (Griffith, 2002). Apart from the endothelial cells that are removed in the balloon injury, macrophages and other leukocytes also express
Cx43 following balloon injury. Although macrophages have the capacity to express Cx43 at mRNA and protein levels (Eugenín et al., 2007; Bermudez-Fajardo et al., 2007), these proteins can not form functional GJ involving in the vascular endothelium proliferation. Likewise, Cx43 in other leukocytes may not form GJ unless reperfusion injury occurs when leukocytes are in contact with endothelial cells (Wang et al., 2005). Furthermore, a study investigating the development of intimal proliferative lesion after balloon catheter de-endothelialization of nude rats shows that macrophages and other leukocytes constitute only approximately $1 \%$ of the carotid neointimal cell population (Ferns et al., 1991). After balloon injury, local platelets, inflammatory cells, SMCs, and endothelial cells can synthesize and secrete a variety of cytokines and growth factors to promote the migration and proliferation of SMCs in the arterial media. GJ and connexins play an important role in the migration and proliferation of SMCs (Wang et al., 2005). During the migration and proliferation of arterial SMCs, GJ transforms from the contractile phenotype to the synthetic phenotype. Recently, it has been shown that $\mathrm{Cx} 43$ expression is markedly enhanced in cultured SMCs at synthetic state when compared with that in those at the contractile state (Yeh et al., 1997; Song et al., 2009), and relatively high expression of $\mathrm{C} \times 43$ was observed in migrating and proliferating SMCs in the neointima following balloon injury (Ruan et al., 2010).

The present study, in agreement with previous findings, demonstrates a significant increase of the mRNA and protein expression of Cx43 in the proliferated VSMCs of rabbit iliac artery after balloon injury. In addition, the mRNA 
and protein expressions of $\mathrm{Cx} 40$ (another important structural protein of GJ channel) were also up-regulated. Although it is unknown which factor triggers the upregulation of $\mathrm{C} \times 40$ and $\mathrm{C} \times 43$, it is evident that cells at the synthetic state can express growth factor receptors and connexin expression is regulated by growth factors in cultured SMCs (Wang et al., 2005; Mensink et al., 1996). Since connexins can be homomeric (six identical connexins) or heteromeric, and the whole GJ channel may be homotypic (two identical connexons) or heterotypic, there is a possibility of diversification. Heteromeric channels have more varied permeability and regulatory properties than homomeric ones and may provide additional options for the regulation of signals transducted through the GJ channels. Heterotypic channels consisting of two different connexins have been described, but only certain heterotypic channels can form functional channels. For instance, the $\mathrm{Cx} 40$ is highly restricted in its ability to form heterotypic channels and is functional when interacting with $\mathrm{C} \times 37$ but not $\mathrm{Cx} 43$. In our study, transmission electron microscopy revealed that abundant and larg GJ was present between SMCs of neointima in the balloon injured arteries, while fewer and smaller GJ found between medial SMCs of arteries from controls, indicating that gap junctional intercellular communication play a crucial role in the migration and proliferation of VSMCs following balloon injury. These results were consistent with the notion that increased Cx40 and Cx43 expression in the neointima of injured arteries may lead to enhanced capacity to direct the intercellular signaling, an event that is closely related to SMC activation and early intimal growth. Both ACE inhibitor (ramipril) and $\mathrm{AT}_{1}$ receptor antagonist (losartan) could prevent the proliferation of VSMCs by inhibiting the mRNA and protein expressions of $\mathrm{C} x 43$.

In contrast to $\mathrm{Cx} 43$, our study also indicated that neither ramipril nor losartan could alter the mRNA expression of $\mathrm{Cx} 40$. Polontchouk et al also showed a similar result (Polontchouk et al., 2002) in which the Cx43 expression and phosphorylation in the cultured neonatal rat ventricular cardiomyocytes increased after incubation with Ang II for $24 \mathrm{~h}$, but no change was found in the Cx40 expression. These findings indicated the expressions of these connexins are differentially regulated (Kwak et al., 2002). Thus, up-regulation of Cx40 mRNA and protein in proliferating VSMCs following balloon injury may not be ascribed to Ang II.

\section{ACKNOWLEDGMENTS}

Sincere thanks to Junzhu Chen, Lihong Wang and Mrs. Dai for the technique support and advice for this study.

\section{REFERENCES}

Bermudez-Fajardo A, Ylihärsilä M, Evans WH, Newby AC, Oviedo-Orta E (2007). CD4+ T lymphocyte subsets express connexin 43 and establish gap junction channel communication with macrophages in vitro. J. Leukoc. Biol., 82(3): 608-12.

Cai W, Ruan LM, Wang YN, Chen JZ (2006). Effects of angiotensin II on connexin 43 of VSMCs in arteriosclerosis. J. Zhejiang. Univ. Sci. B., 7(8): 648-653.

Carlen PL, Skinner F, Zhang L, Naus C, Kushnir M, Perez Velazquez JL (2000). The role of gap junctions in seizures. Brain. Res. Brain. Res. Rev., 32(1): 235-41.

Dendorfer A, Dominiak P, Schunkert H (2005). ACE inhibitors and angiotensin II receptor antagonists. Handbook Exp. Pharmacol., (170): 407-42.

Eugenín EA, González HE, Sánchez HA, Brañes MC, Sáez JC (2007). Inflammatory conditions induce gap junctional communication between rat Kupffer cells both in vivo and in vitro. Cell. Immunol., 247(2): 103-10

Ferns GA, Reidy MA, Ross R (1991). Balloon catheter deendothelialization of the nude rat carotid. Response to injury in the absence of functional T lymphocytes. Am. J. Pathol., 138(4): 104557.

Geng S, Sun B, Liu S, Wang J (2007). Up-regulation of connexin 43 and gap junctional intercellular communication by Coleusin Factor is associated with growth inhibition in rat osteosarcoma UMR106 cells. Cell. Biol. Int., 31(11): 1420-7.

Griffith TM (2002). Endothelial control of vascular tone by nitric oxide and gap junctions: a haemodynamic perspective. Biorheology, 39(34): 307-18.

Harris AL (2001). Emerging issues of connexin channels: biophysics fills the gap. Q. Rev. Biophys., 34(3): 325-472.

Isakson BE, Kronke G, Kadl A, Leitinger N, Duling BR (2006). Oxidized phospholipids alter vascular connexin expression, phosphorylation, and heterocellular communication. Arterioscler. Thromb. Vasc. Biol., 26(10): 2216-21

Jara PI, Boric MP, Sáez JC (1995). Leukocytes express connexin 43 after activation with lipopolysaccharide and appear to form gap junctions with endothelial cells after ischemia-reperfusion. Proc. Nat. Acad. Sci. USA., 18-92(15): 7011-5.

Kanaporis G, Brink PR, Valiunas V (2011). Gap junction permeability: selectivity for anionic and cationic probes. Am. J. Physiol. Cell. Physiol., 300(3): C600-9.

Kjenseth A, Fykerud T, Rivedal E, Leithe E (2010). Regulation of gap junction intercellular communication by the biquitin system. Cell. Signal, 22(9): 1267-73.

Kwak BR, Mulhaupt F, Veillard N, Gros DB, Mach F (2002). Altered pattern of vascular connexin expression in herosclerotic plaques. Arterioscler. Thromb. Vasc. Biol., 1-22(2): 225-30.

Kwak BR, Veillard N, Pelli G, Mulhaupt F, James RW, Chanson M, Mach F (2003). Reduced connexin43 expression inhibits atherosclerotic lesion formation in low-density lipoprotein receptordeficient mice. Circulation, 107(7): 1033-9.

Matsushita T, Rama A, Charolidi N, Dupont E, Severs NJ (2007). Relationship of connexin43 expression to phenotypic modulation in cultured human aortic smooth muscle cells. Eur. J. Cell. Biol., 86(10): 617-28.

Mensink A, Brouwer A, Van den Burg EH, Geurts S, Jongen WM, Lakemond CM, Meijerman I, Van der Wijk T (1996). Modulation of intercellular communication between smooth muscle cells by growth factors and cytokines. Eur. J. Pharmacol., 22-310(1): 73-81.

Rama A, Matsushita T, Charolidi N, Rothery S, Dupont E, Severs NJ (2006). Up-regulation of connexin43 correlates with increased synthetic activity and enhanced contractile differentiation in TGFbeta-treated human aortic smooth muscle cells. Eur. J. Cell. Biol., 85(5): 375-86.

Ruan LM, Cai W, Chen JZ, Duan JF (2010). Effects of Losartan on expression of connexins at the early stage of atherosclerosis in rabbits. Int. J. Med. Sci., 8-7(2): 82-9.

Rudijanto A (2007). The role of vascular smooth muscle cells on the pathogenesis of atherosclerosis. Acta. Med. Indones, 39(2): 86-93.

Shyu KG, Chen CC, Wang BW, Kuan P (2001). Angiotensin II receptor antagonist blocks the expression of connexin43 induced by cyclical mechanical stretch in cultured neonatal rat cardiac myocytes. J. Mol. Cell Cardiol., 33(4): 691-8.

Song M, Yu X, Cui X, Zhu G, Zhao G, Chen J, Huang L (2009). 
Blockade of connexin 43 hemichannels reduces neointima formation after vascular injury by inhibiting proliferation and phenotypic modulation of smooth muscle cells. Exp. Biol. Med (Maywood). 234(10): 1192-200.

Sun Y (2010). Intracardiac renin-angiotensin system and myocardial repair/remodeling following infarction. J. Mol. Cell. Cardiol., 48(3): 483-9.

Wang L, Chen J, Sun Y, Zhang F, Zhu J, Hu S, Wang DH (2005). Regulation of connexin expression after balloon injury: possible mechanisms for antiproliferative effect of statins. Am. J. Hypertens, 18(9-1): 1146-53.

Wang LH, Chen JZ, Sun YL, Zhang FR, Zhu JH, Hu SJ, Wang DH (2005). Statins reduce connexin40 and connexin43 expression in atherosclerotic aorta of rabbits. Int. J. Cardiol., 28-100(3): 467-75.
Yeh HI, Lupu F, Dupont E, Severs NJ (1997). Upregulation of connexin43 gap junctions between smooth muscle cells after balloon catheter injury in the rat carotid artery. Arterioscler. Thromb. Vasc. Biol., 17(11): 3174-84.

Zhao LL, Chen HJ, Chen JZ, Yu M, Ni YL, Zhang WF (2008). Losartan reduced connexin43 expression in left ventricular myocardium of spontaneously hypertensive rats. J. Zhejiang. Univ. Sci. B., 9(6): 448-454. 